\title{
Assessment of organizational well-being in an Italian General Hospital after an organizational change
}

\author{
Dina Guglielmi, ${ }^{1}$ Maria Cristina Florini, ${ }^{2}$ Greta Mazzetti, ${ }^{1}$ Marco Depolo, ${ }^{3}$ Enza Calabrò, ${ }^{4}$ Sonia Miglioli, ${ }^{5}$ \\ Monica Mariani, ${ }^{5}$ Giorgio Cioni ${ }^{6}$ \\ ${ }^{1}$ Department of Educational Sciences, University of Bologna, Bologna; ${ }^{2}$ Service for Human Resources Evaluation and \\ Valorization, AUSL Modena; ${ }^{3}$ Department of Psychology, University of Bologna, Bologna; ${ }^{4}$ Nursing Department, Hospital of \\ Pavullo nel Frignano (MO); ${ }^{5}$ Internal Medicine Unit, Intensive Care Section, Nursing Department, Hospital of Pavullo nel \\ Frignano (MO); ${ }^{6}$ Department of Internal Medicine and Rehabilitation, Hospital of Pavullo nel Frignano (MO), AUSL Modena, \\ Italy
}

\begin{abstract}
Nowadays, the intensity of care organizational model has been adopted in several Italian hospitals in order to create specific areas dedicated to patients reporting homogeneous needs of care. The present paper aims at describing the organizational intervention Inside the change, designed to explore the context and assess the impact of the implementation of the Intensity of cure model in an Italian hospital. Inside the change was composed of two segments: i) the evaluation of attitudes toward change and workers' well-being (quantitative phase); ii) the conduction of a consulting process aimed to identify critical issues and the related improvement actions (qualitative phase). The results showed that workers (i.e., physicians, nurses, healthcare assistants) involved in the change process showed higher levels of work-related well-being symptoms. In line with this result, the second stage of the intervention had the goal of improving workers' involvement in organizational change, together with the identification of suitable improvement actions. Data collected one year after the intervention suggest that the whole performance of healthcare organizations may be enhanced by investments in monitoring and improving organizational processes, particularly for those focused on HR management.
\end{abstract}

\section{Introduction}

\section{The organizational change at the Internal Medicine Unit of the Pavullo nel Frignano Hospital}

During the last 20 years, inpatients arriving at our hospitals have deeply changed. Nowadays, they are

Correspondence: Giorgio Cioni, Department of Internal Medicine and Rehabilitation, Hospital of Pavullo nel Frignano (MO), AUSL Modena, Italy.

E-mail: g.cioni@ausl.mo.it

Key words: Intensity of care; organizational change; health system; organizational well-being.

Conflict of interest: the authors declare no potential conflict of interest.

Received for publication: 14 October 2016.

Accepted for publication: 16 October 2016.

This work is licensed under a Creative Commons Attribution NonCommercial 4.0 License (CC BY-NC 4.0).

CCopyright D. Guglielmi et al., 2017

Licensee PAGEPress, Italy

Italian Journal of Medicine 2017; 11:95-101

doi:10.4081/itjm.2017.788 mainly elder people, affected by complex polipathologies that require compound treatments, and are often embedded in relevant social care needs.

The intensity of care organizational model seems to represent the most appropriate solution in order to treat these cases, together with an integrated approach between hospitals and local (decentralized) National Health Service.

The hospital involved in the current study has 140 beds within General Medicine, Surgery, Orthopedics, and Obstetrics Recovery Units. In July 2012, the Board of Administrators requested a massive reorganization, where units were no longer based on the specific pathology under treatment, but rather on the intensity of care needed by inpatients.

The planning phase was quite quick, and the real re-organization started in 2012. The Director of the Internal Medicine Unit, together with two nurse coordinators, was in charge for the new unit. The recovery area, located across two floors, was divided as follows: i) 44 beds for acute inpatients (average intensity of care), including a Stroke Care Unit (between high and average intensity of care). The mission was to treat acute inpatients, with complex medical conditions to be dealt within the hospital; ii) 4 beds for critical inpatient (semi-intensive care unit with high intensity of care), already present since 2005 . The mission was to manage inpatients suffering from severe 
pathologies and vital organs impairment, as well as surgical inpatients in collaboration with surgeons and anesthetists; iii) 35 beds for post-acute and rehabilitation inpatients: Post-acute Internal Medicine, at lower intensity of care. The mission was to manage inpatients arriving from other units, with acute phase partially solved and needing stabilization, re-activation and/or rehabilitation. Difficult hospital discharges were also in charge to this area.

During the reorganization process, several documents were produced, discussed and shared within the staff in order to define the following issues: i) mission and resources (human, logistic and technological) for each area; ii) clinical responsibilities, work schedules, and training needs for all the hospital staff; iii) criteria for the assignment of inpatients to different areas; iv) responsibilities and operating models, benchmarks and goals for inpatients' admission, transfer and discharge.

This organizational model has been tested for two years. Then, the hospital General Manager (in collaboration with the Organizational Health Unit) designed an intervention aimed to assess the outcomes of this reorganization, both in terms of organizational processes - in order to identify and handle critical issues - and in terms of workers' well-being.

The main purpose of this paper is to describe the organizational intervention called Inside the change, which was designed to explore the context and assess the impact of reorganization after two years.

\section{The Inside the change intervention}

The intervention was composed of two segments: i) a quantitative analysis, aimed to assess attitudes toward change, and workers' well-being; ii) a consulting process, aimed to identify critical issues and the related improvement actions.

\section{Workers' well-being}

\section{Materials and Methods}

The participants consisted of 88 healthcare workers (out of a total of 101) that accepted to participate in the research. The majority of the sample were women $(81 \%)$, the mean age was 43.44 years [standard deviation $(\mathrm{sd})=7.37]$. Most participants held a High School degree (41.7\%) and the average seniority in the healthcare sector was 13.40 years $(\mathrm{sd}=8.56)$. With regard to the professional profiles involved, the sample was mainly composed of nurses (59.5\%), healthcare assistants (26.2\%) and physicians (14.3\%). Participants were asked to fill in a structured, anonymous questionnaire aimed at investigating several psychosocial aspects of work and work-related outcomes. The anonymity and confidentiality of participants' answers were warranted in a letter attached to each ques- tionnaire and signed by the coordinator of the University research unit.

The scales employed in the questionnaire are listed below.

- Commitment to change was measured using 6 items ${ }^{1}$ rated on a seven-point rating scale ranging from $1=$ strongly disagree to $7=$ strongly agree .

- Emotional exhaustion, the central strain dimension of burnout, was measured using the 6-item scale of the Maslach Burnout Inventory - general survey. ${ }^{2}$ All items were scored on a seven-point rating scale ranging from $0=$ never to $6=$ always.

- Work engagement was measured using the 9-item version of the Utrecht Work Engagement Scal (UWES-9). ${ }^{3}$ All items were scored on a seven-point rating scale ranging from $0=$ never to $6=$ always .

- Inadequate preparation was assessed using 3 items taken from the Nursing Stress Scale. ${ }^{4}$ All items were scored on a four-point frequency scale ranging from $1=$ never to $4=$ very often .

- Role conflict was measured with 5 items ${ }^{5}$ assessed on a five-point scale ranging from $1=$ strongly disagree to 5=strongly agree.

- Opportunity for professional development was measured with a 5-item scale. ${ }^{6}$ Responses were given on a frequency scale ranging from $1=$ never to $5=$ very often.

Role clarity was assessed with 4 items ${ }^{5}$ rated on a five-point rating scale ranging from $1=$ strongly disagree to 5=strongly agree.

- Supervisors support and Co-workers support were measured with 8 items (4 items each) taken from the Job Content Questionnaire. ${ }^{7}$ All items were rated on a four-point rating scale ranging from $1=$ strongly disagree to $4=$ strongly agree.

- Information about change was investigated through a self-constructed scale that included 7 items aimed at assessing to what extent workers were informed about the organizational change, its purpose and the foreseen impact. Responses were given on a seven-point rating scale ranging from $1=$ strongly disagree to $7=$ strongly agree .

\section{Results}

Means, standard deviations, correlations, and internal consistencies of scales for all study variables are presented in Table 1. Pearson's correlations indicate that all relationships between the study variables were significant in the expected direction. Moreover, the internal consistencies of the scales satisfied the criterion of 0.65 as a minimum threshold for an acceptable Cronbach's $\alpha$ coefficient $^{8}$ (Table 1, values in brackets).

In the current study, the average score on work engagement $(\mathrm{M}=4.90, \mathrm{sd}=0.85)$ was higher than the average engagement score reported by the normative sample of the UWES-9 $(\mathrm{N}=12.631, \mathrm{M}=4.05$, 
$\mathrm{sd}=1.19) .{ }^{9}$ Moreover, the level of emotional exhaustion of participants in this research $(\mathrm{M}=18.26$, $\mathrm{sd}=6.60)$ was on average higher than the score reported in several studies among Italian healthcare workers. For instance, a research by Guglielmi and colleagues ${ }^{10}$ on 159 nurses working in a hospital in the North of Italy reported a mean score on emotional exhaustion equal to $\mathrm{M}=14.19$ ( $\mathrm{sd}=7.74)$. In a similar vein, in 2012 Vignoli et al. ${ }^{11}$ conducted a study on a sample of 200 healthcare professionals working in a public and a private hospital both located in the same northern Italian region, and indicated an average value of emotional exhaustion equal to $\mathrm{M}=13.29$ ( $\mathrm{sd}=7.99)$.

In order to analyze differences between work roles, the mean values reported by nurses, physicians and healthcare assistants have been compared.

Accordingly, one-way analysis of variance (ANOVA) and Tukey's honest significant difference post hoc comparison were performed to determine differences between work roles. Results revealed a significant difference concerning three study variables. With reference to the level of Commitment to change, ANOVA results indicated a different perception between groups: $\mathrm{F}(2.81)=6.68, \mathrm{P}=0.002$. In particular, nurses reported a lower commitment to change $(\mathrm{M}=4.22, \mathrm{sd}=1.38)$ compared to physicians $(\mathrm{M}=5.69$, $\mathrm{sd}=1.22)$. In a similar vein, these roles showed a different perception of Supervisor support $[\mathrm{F}(2.81)=8.44$, $\mathrm{P}=0.000$ ] and Information about change $[\mathrm{F}(2.81)=4.98, \mathrm{P}=0.009]$. Thus, nurses perceived a poorer social support provided by their supervisor $(\mathrm{M}=2.63, \mathrm{sd}=0.11)$ compared to physicians $(\mathrm{M}=3.54$, $\mathrm{sd}=0.15$ ). Moreover, the perceived level of information about the adjustment of hospital internal medicine was significantly lower among nurses $(\mathrm{M}=3.72$, $\mathrm{sd}=0.23)$ in comparison to physicians $(\mathrm{M}=5.11$, $\mathrm{sd}=0.42$ ). These results are presented in Figure 1, although emotional exhaustion is omitted for reasons of clarity. Nonetheless, ANOVA results indicated a nonsignificant difference between groups: the average score on emotional exhaustion was $\mathrm{M}=18.76$, $\mathrm{sd}=6.56$ among nurses; $\mathrm{M}=15.41, \mathrm{sd}=7.06$ among physicians; $\mathrm{M}=18.55, \mathrm{sd}=6.53$ among healthcare assistants.

In addition, the total sample was divided into two groups on the basis of the median (Mdn) score for the Commitment to change dimension, and the differences in all the study variables were explored. Although the dichotomization of continuous variables produces information loss and may thus decrease statistical power, ${ }^{12}$ this procedure allowed to obtain a detailed insight into the relationship between the degree of commitment to the organizational change and a wide range of psychosocial aspects of work, as well as work-related conditions (i.e., work engagement and emotional exhaustion). Participants were categorized into groups based on their scores, which are split around the median (here, Mdn Commitment to change $=4.33$ ). Then, differences between participants exhibiting low and high levels of commitment to change were calculated using Student's $t$-test. These results are reported in Table 2.

Concerning the work-related outcomes under investigation, a greater commitment to change was associated with lower levels of emotional exhaustion and a higher degree of work engagement. In addition, workers highly committed to change perceived wider opportunities for professional development, a greater support provided by their supervisor, and they were more aware of the aims and effects of the organizational change (information about change).

Table 1. Means, standard deviation, Cronbach's $\alpha$ coefficients (in brackets), and correlations among the study variables $(\mathrm{n}=\mathbf{8 8})$.

\begin{tabular}{|c|c|c|c|c|c|c|c|c|c|c|c|c|}
\hline & \multirow[b]{2}{*}{ M } & \multirow[b]{2}{*}{ sd } & \multicolumn{9}{|c|}{$r$} & \multirow[b]{2}{*}{10} \\
\hline & & & 1 & 2 & 3 & 4 & 5 & 6 & 7 & 8 & 9 & \\
\hline Commitment to change & 4.53 & 1.44 & $(0.91)$ & - & - & - & - & - & - & - & - & - \\
\hline Emotional exhaustion & 18.26 & 6.60 & $-0.41 * * *$ & $(0.78)$ & - & - & - & - & - & - & - & - \\
\hline Work engagement & 4.90 & 0.85 & $0.38 * * *$ & $-0.33^{* *}$ & $(0.84)$ & - & - & - & - & - & - & - \\
\hline Inadequate preparation & 2.11 & 0.46 & -0.10 & -0.01 & $-0.31 * *$ & $*(0.65)$ & - & - & - & - & - & - \\
\hline Role conflict & 4.08 & 0.89 & -0.150 & $0.47 * * *$ & $-0.27 *$ & $0.24 *$ & $(0.83)$ & - & - & - & - & - \\
\hline Opportunity for professional development & 3.76 & 0.76 & $0.46 * * *$ & $-0.34 * *$ & $0.35^{* *}$ & 0.06 & $-0.31 *$ & $*(0.83)$ & - & - & - & - \\
\hline Role clarity & 3.64 & 0.75 & 0.09 & -0.03 & 0.12 & $-0.25 *$ & 0.05 & $0.28^{* *}$ & $(0.67)$ & - & - & - \\
\hline Supervisor support & 2.86 & 0.77 & $0.44 * * *$ & $-0.29 * *$ & $0.32 * *$ & -0.15 & -0.16 & $0.52 * * *$ & $0.36^{* *}$ & $(0.88)$ & - & - \\
\hline Co-workers support & 3.16 & 0.46 & 0.16 & -0.04 & 0.20 & -0.07 & -0.04 & $0.37 * * *$ & 0.17 & $0.28^{* *}$ & $(0.67)$ & - \\
\hline Information about change & 4.10 & 1.58 & $0.43 * * *$ & -0.14 & 0.18 & -0.05 & -0.11 & $0.43 * * *$ & $0.26^{*}$ & $0.58 * * *$ & 0.16 & $(0.94)$ \\
\hline
\end{tabular}

$\mathrm{M}$, mean; sd, standard deviation. ${ }^{\mathrm{P}} \mathrm{P}<0.05 ; * * \mathrm{P}<0.01 ; * * * \mathrm{P}<0.001$. 


\section{The consulting process}

The consulting process was based on a workshop approach that involved the whole hospital staff: nurses, physicians, and healthcare assistants. The first activity implemented within the consulting process was a problem-finding exercise through a brain storming focused on change, the construction of a metaphor for an idea of intensity of care hospital, and a SWOT analysis (strengths, weaknesses, opportunities and threats) (Table 3).

The Nominal Group Technique (NGT) ${ }^{13}$ was ap-

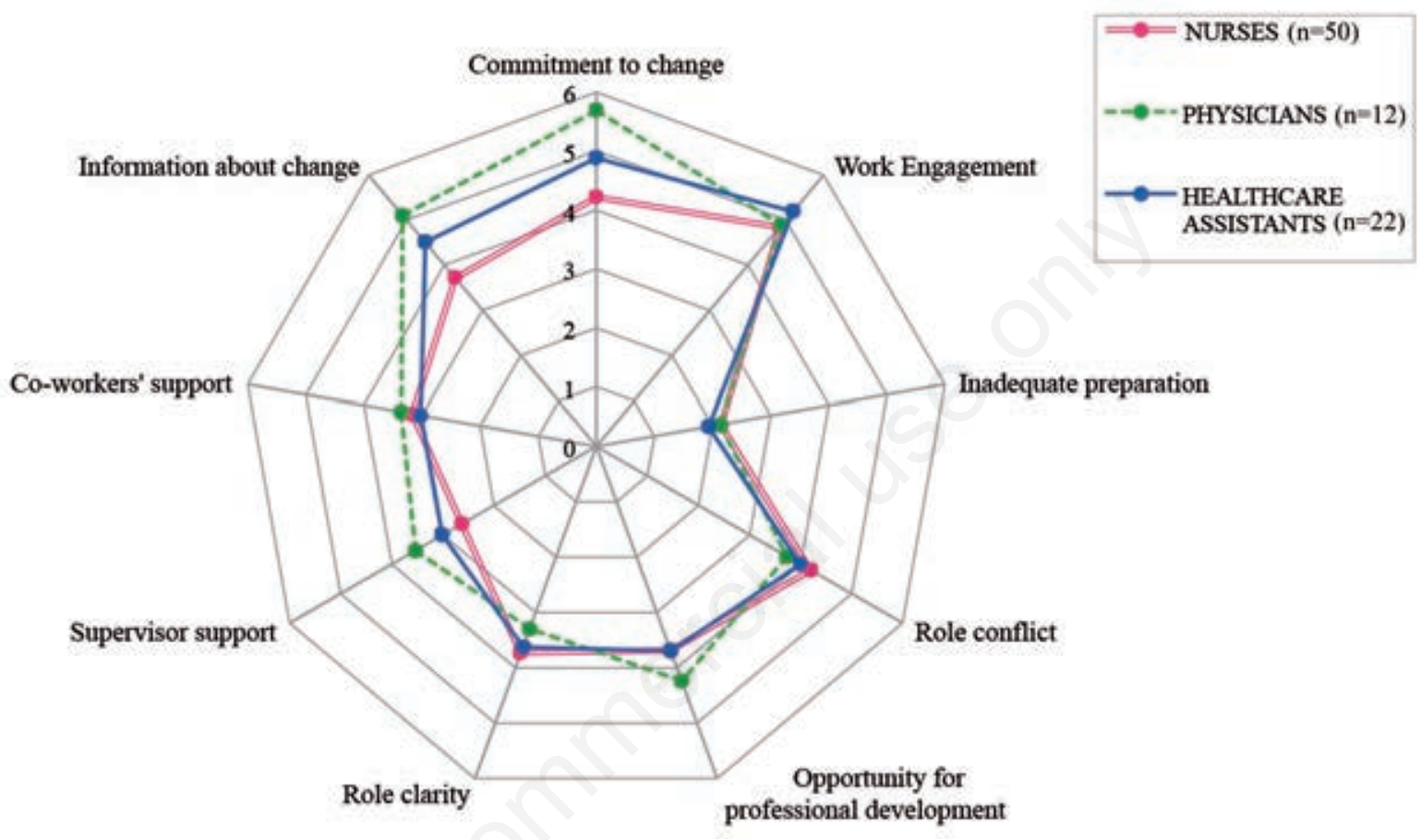

Figure 1. Comparison between work roles $(\mathrm{n}=\mathbf{8 8})$.

Table 2. Characteristics of the low and high Commitment to change subgroups.

\begin{tabular}{lcccc}
\hline & \multicolumn{2}{c}{$\begin{array}{c}\text { Commitment to change } \\
\text { (Median=4.33) }\end{array}$} & \multicolumn{1}{c}{ Student's -test } \\
& Low (n=47) & High (n=41) & t(df) & P \\
\cline { 2 - 5 } & $\mathbf{M}(\mathbf{s d})$ & $\mathbf{M}(\mathbf{s d})$ & & \\
\hline Emotional exhaustion & $20.47(5.70)$ & $15.73(6.70)$ & $3.59(86)$ & 0.001 \\
\hline Work engagement & $4.59(0.97)$ & $5.25(0.47)$ & $-3.94(86)$ & 0.000 \\
\hline Inadequate preparation & $2.13(0.46)$ & $2.09(0.46)$ & $0.46(86)$ & $\mathrm{ns}$ \\
\hline Role conflict & $4.14(0.82)$ & $4.00(0.96)$ & $0.71(86)$ & $\mathrm{ns}$ \\
\hline Opportunity for professional development & $3.50(0.69)$ & $4.06(0.74)$ & $-3.70(86)$ & 0.000 \\
\hline Role clarity & $3.55(0.80)$ & $3.73(0.69)$ & $-1.11(86)$ & $\mathrm{ns}$ \\
\hline Supervisor support & $2.55(0.70)$ & $3.21(0.70)$ & $-4.46(86)$ & 0.000 \\
\hline Co-workers' support & $3.12(0.50)$ & $3.20(0.42)$ & $-0.79(86)$ & $\mathrm{ns}$ \\
\hline Information about change & $3.50(1.35)$ & $4.78(1.56)$ & $-4.13(86)$ & 0.000 \\
\hline
\end{tabular}

M, mean; sd, standard deviation; df, degree of freedom; ns, not significant. 
plied in order to identify critical issues and priority threats through the active participation of hospital staff. The NGT is defined as a group process that encompasses problem identification, solution generation, and decision-making. This technique has become the most popular approach to group brainstorming and could be employed in groups of different sizes: by a vote, NGT allows to take into account everyone's opinion rather than focusing on the opinion shared by the largest group of participants. The critical issues and priority threats through the NGT were: risen probability of error; lacking re-organization of work plans; increased inpatients turnover; feelings of disorientation by inpatients and their families; workload increase; increased bureaucracy.

The core aim of the SWOT analysis was to involve the hospital staff in a process of identification and assessment of strengths, weaknesses, opportunities and threats associated with the organizational change. Usually, the main goal of a SWOT analysis is to identify the strengths and weaknesses of an organization and the opportunities and threats arising from the en- vironment. This identification should lead to the development of strategies that leverage on strengths, eliminate weaknesses, exploit opportunities and counteract threats. The threats and opportunities identified were summarized and, subsequently, they have been re-interpreted and categorized.

The first step was focused on problem setting, an activity that allowed an in-depth analysis of weaknesses and threats. Participants were asked to answer the following questions individually and, next, within small groups: i) What is the problem? ii) What are the causes of the problem? iii) What are the consequences of the problem on individuals, groups and organization?

Then, a problem-solving activity was carried out in order to identify potential solutions to the weaknesses and threats previously found and to overcome them through improvement actions, by asking the following questions: Which actions could be implemented in order to find a proper solution to the problem (weakness and threat)? Improvement actions were conceived also weighing up feasibility criteria (Table 4).

Table 3. Strengths, weaknesses, opportunities and threats (SWOT) analysis.

\begin{tabular}{ll}
\hline SWOT analysis - change & Weaknesses \\
\hline Strengths & Increase of inpatients turnover \\
\hline Reduced hospitalization & $\begin{array}{l}\text { Poor integration between hospital units and the surrounding territory } \\
\text { (identified as a crucial aspect in the reorganization project, but still lacking) }\end{array}$ \\
\hline Assistance more suitable to inpatients needs & $\begin{array}{l}\text { Physical and logistical difficulties } \\
\text { Work plans to be updated } \\
\text { Risen probability of error }\end{array}$ \\
\hline More defined discharge process & Threats \\
\hline Opportunities & Increased bureaucracy \\
\hline Greater collaboration & Workload Increase \\
\hline Resource optimization & Feelings of disorientation by inpatients and their families \\
\hline $\begin{array}{l}\text { Greater integration between hospital and the surrounding } \\
\text { territory }\end{array}$ &
\end{tabular}

Increased autonomy and opportunity for professional development

Table 4. Improvement actions.

\begin{tabular}{ll}
\hline Critical issue & Improvement action \\
\hline Risen probability of error & $\begin{array}{l}\text { To reorganize the resources available in the work context in terms of human resources, work plans } \\
\text { and logistics and to improve the efficiency of communication processes within and between units }\end{array}$ \\
\hline Lacking re-organization of work plans & $\begin{array}{l}\text { To increase staff participation in defining new work plans suitable for the new Intensity of Care } \\
\text { organizational model, and create the role of Case Manager }\end{array}$ \\
\hline Increased inpatients turnover & $\begin{array}{l}\text { Improve the management of admission and discharge processes through a greater involvement of } \\
\text { territorial assistance structures and the Emergency Department in the Intensity of care project }\end{array}$ \\
\hline Increased bureaucracy & $\begin{array}{l}\text { Reduce bureaucracy through the standardization, simplification and digitalization of forms and } \\
\text { documents }\end{array}$ \\
\hline
\end{tabular}




\section{From weaknesses and threats to improvement actions}

Despite the difficulties arising from the controversial decision not to keep the Geriatrics Unit, present in the hospital for a long time, and from the necessity to merge work teams previously separate, the reorganization process started in 2012 followed a clinical and operational path essentially in line with the expectations of the hospital management. A critical issue identified at the beginning of the reorganization was represented by the high rate of internal transfers of inpatients resulting from the decreased number of beds assigned to the Emergency Department. To this connection, the following corrective measures were implemented in 2013/2014: the adoption of identical and new inpatients beds throughout the unit; integrated activity of the hospital staff with repeated departmental meetings; job rotation of physicians working within the hospital; the adoption of shared protocols and patterns; the implementation of a management information system (with a specific training to the whole hospital staff); the presence of a single operating system throughout the unit.

Results obtained from the above-mentioned questionnaire and the consulting process carried out at the beginning of 2015 within the frame of the Inside the change intervention, revealed the presence of positive outcomes, such as the attainment of budget goals, along with some critical issues. In particular, the implementation of the intensity of care organizational model seemed to be tricky especially for nurses. Accordingly, the unit management defined and implemented an improvement strategy aimed to cope with the critical issues stemming from the reorganization process. The previous section described the main organizational problems reported by the unit staff, and the proposed improvement actions.

Among them, the unit staff and management chose the following priorities:

- To allow the admission to the Low Intensity of Care Area for a specific category of inpatients requesting hospitalization. These inpatients had been already recognized in the reorganization document produced in 2012 as inpatients early transferable to Low Intensity of Care Area.

- To create a task force in the unit with the main aim to produce an Integrated work plan for nurses, physicians and healthcare workers. The key points of this document, implemented in late 2015, were: i) multidisciplinary, essential for dealing with complex medical conditions that require a compound assistance that could not be provided autonomously by a single staff member; ii) collaborative practice between professionals in different domains, as a pre-condition for a high-quality care system; iii) integrated work plan, as a crucial factor in order to guarantee an efficient time management strategy and to arrange team meetings.

Moreover, this document addressed the following topics: staff briefing; joint medical examination from doctor and nurse; inpatient admission procedure; creation of a shared document (labeled as problems list) reporting all the information related to each inpatient in order to consent a clear transmission of these data within the staff.

The intervention considered both weaknesses and strengths of the organizational change, keeping in mind that the involvement of workers in the change process may prevent them from work-related negative outcomes. Accordingly, data collected through the questionnaire indicated that workers engaged with the change process showed higher levels of work-related well-being symptoms. For instance, the ratings provided by participants who completed the questionnaire both before and after the intervention $(\mathrm{N}=38)$ revealed a significant decrease in the average score of emotional exhaustion after the intervention $(\mathrm{M}=16.36$, $\mathrm{sd}=5.75)$ than before its implementation $(\mathrm{M}=18.64$, $\mathrm{sd}=6.74) ; \mathrm{t}(41)=2.91, \mathrm{P}=0.006$.

In line with this result, the second stage of the intervention had the goal of improving workers' involvement in organizational change, together with the identification of suitable improvement actions. One year later, the positive feedback from the Internal Medicine unit indicated that the whole performance of healthcare organizations may benefit from investments in managing effectively organizational changes, especially for those affecting the human resources working in these settings.

\section{References}

1. Herscovitch L, Meyer JP. Commitment to organizational change: extension of a three component model. J Appl Psychol 2002;87:474-87.

2. Maslach C, Jackson SE Leiter MP. Maslach burnout inventory; manual, 3rd ed. Palo Alto, CA: University of California, Consulting Psychologists Press; 1996.

3. Schaufeli WB, Bakker AB, Salanova M. The measurement of work engagement with a short questionnaire: a crossnational study. Educ Psychol Meas 2006;66:701-16.

4. Gray-Toft P, Anderson J. The nursing stress scale: development of an instrument. J Behav Assess 1981;3:11-23.

5. Rizzo JR, House RJ, Lirtzman SI. Role conflict and ambiguity in complex organizations. Admin Sci Quart 1970;150-63.

6. Borgogni L, Galati D, Petitta L; Centro Formazione A. Schweitzer. Questionario di check-up organizzativo: manuale. Firenze: Organizzazioni Speciali; 2005.

7. Karasek R, Brisson C, Kawakami N, et al. The Job Content Questionnaire (JCQ): An instrument for internationally comparative assessments of psychosocial job characteristics. J Occup Health Psych 1998;3:322-55. 
8. DeVellis RF. Scale development: theory and applications, 2nd ed. Thousand Oaks, CA: SAGE; 2003.

9. Schaufeli WB, Bakker AB. UWES - Utrecht work engagement scale preliminary manual (Version 1.1). Utrecht: Utrecht University; 2004.

10. Guglielmi D, Simbula S, Depolo M, Violante F. La rilevazione dei fattori di rischio psicosociale alla luce del job demands-resources model. Risorsa Uomo 2011; 16:19-32.

11. Vignoli M, Guglielmi D, Simbula S, Depolo M. Positive and negative effects of perceived inequity on Italian healthcare workers: the role of social support. Healthc Profess J 2012;1:5-15.

12. MacCallum RC, Zhang S, Preacher KJ, Rucker DD. On the practice of dichotomization of quantitative variables. Psychol Methods 2002; 7:19-40.

13. Delbecq AL, VandeVen AH. A group process model for problem identification and program planning. J Appl Behav Sci 1971;7:466-91. 